\title{
SÍNTESES QUíMICA E ENZIMÁTICA DE PEPTÍDEOS: PRINCÍPIOS BÁSICOS E APLICAÇõeS
}

\author{
Alessandra Machado, Cleber W. Liria, Patrícia B. Proti, César Remuzgo e M. Terêsa M. Miranda* \\ Departamento de Bioquímica, Instituto de Química, Universidade de São Paulo, Av. Prof. Lineu Prestes, 748, \\ 05508-900 São Paulo-SP
}

Recebido em 17/9/03; aceito em 27/11/03; publicado na web em 17/6/04

\begin{abstract}
CHEMICAL AND ENZYMATIC PEPTIDE SYNTHESES: BASIC ASPECTS AND APPLICATIONS. This review begins with a brief discussion of the biological importance and chemical features of peptides. A description of the existing synthetic methods follows with emphasis on the basic aspects of the chemical and enzymatic syntheses. Techniques used to purify and characterize the synthesized peptides are also discussed. Finally, a few applications of the final products in chemistry, biochemistry, immunology and medicine are presented, such as identification and quantification of naturally occurring peptides, inspection of structureactivity relationships, therapeutics, development and/or improvement of analytical techniques and search for new vaccines.
\end{abstract}

Keywords: peptides; synthesis; applications of synthetic peptides.

\section{A DIVERSIDADE FUNCIONAL E QUÍMICA DOS PEPTÍDEOS}

Os peptídeos são biomoléculas que contém de dois a dezenas de resíduos de aminoácidos unidos entre si através de ligações peptídicas. Se comparados às proteínas, são quimicamente mais versáteis, pois podem ser amidados ou esterificados em suas carboxilas terminais, acetilados em seus grupos amino terminais, fosforilados ou sulfatados em um ou mais resíduos (serina, treonina ou tirosina), lineares, semicíclicos (geralmente via uma ou mais ligações dissulfeto intra- ou intercadeias peptídicas) ou cíclicos (via ligação entre os grupos amino e carboxila dos aminoácidos terminais). Muitos contêm um ácido piroglutâmico como resíduo $\mathrm{N}$-terminal, outros apresentam Daminoácidos e outros, ainda, possuem aminoácidos não usuais ${ }^{1}$.

Os peptídeos são também extremamente diversificados em termos funcionais. Muitos atuam como hormônios ou fatores liberadores destes, enquanto outros são neuropeptídeos, neurotransmissores, toxinas, antibióticos naturais, adoçantes ou substratos de proteases. $\mathrm{Na}$ verdade, vários deles fazem parte de nossas conversas sem que nos apercebamos disto: é o caso do aspartame, da insulina, da ocitocina e de diversas drogas comerciais, que consistem em antagonistas de peptídeos naturais ou em inibidores de enzimas envolvidas na sua produção e liberação no organismo ${ }^{2-4}$.

A Tabela 1 fornece alguns exemplos desta diversidade funcional e química. Todo este conhecimento começou a ser acumulado principalmente a partir da década de 50, quando vários peptídeos ativos foram descobertos e tiveram as suas estruturas químicas determinadas. Foi o caso de diversos hormônios que controlam o metabolismo animal (glucagon e insulina, p.ex.) e de outros que desempenham papéis específicos em nosso organismo (ocitocina, vasopressina e o hormônio estimulador de melanócitos, p. ex. $)^{10}$.

Estas descobertas geraram um enorme interesse por esta classe de compostos e por metodologias para seu isolamento, análise, purificação, identificação e quantificação, as quais passaram a ser sistematicamente estudadas e aprimoradas. Em paralelo, deparou-se com a necessidade de sintetizar estas moléculas e análogos (derivados com modificações pontuais) em escalas variadas, pois somente de posse dos sintéticos poder-se-ia realizar os estudos fisiológicos, quí-

Tabela 1. Diversidade funcional e química dos peptídeos

\begin{tabular}{|c|c|c|c|}
\hline Nome & Seqüência & Função & Ref. \\
\hline Angiotensina II & Asp-Arg-Val-Tyr-Ile-His-Pro-Phe & Hormônio hipertensor & 5 \\
\hline Somatostatina & $\begin{array}{l}\text { ciclo(3-14) Ala-Gly-Cys-Lys-Asn-Phe- } \\
\text { Phe-Trp-Lys-Thr-Phe-Thr-Ser-Cys }\end{array}$ & Fator inibidor da liberação de somatotropina & 6 \\
\hline$\alpha$-Conotoxina ImI & $\begin{array}{l}\text { ciclo(2-8,3-14) Gly-Cys-Cys-Ser-Asp- } \\
\text { Pro-Arg-Cys-Ala-Trp-Arg-Cys- } \mathrm{NH}_{2}\end{array}$ & $\begin{array}{l}\text { Bloqueador do receptor nicotínico de acetilcolina } \\
\text { no sistema nervoso central }\end{array}$ & 7 \\
\hline $\begin{array}{l}\text { Fragmento } 22-52 \text { da } \\
\text { adrenomedulina humana }\end{array}$ & $\begin{array}{l}\text { Thr-Val-Gln-Lys-Leu-Ala-His-Gln-Ile- } \\
\text { Tyr-Gln-Phe-Thr-Asp-Lys-Asp-lys-Asp- } \\
\text { Asn-Val-Ala-Pro-Arg-ser-Lys-Ile-Ser-Pro- } \\
\text { Gln-Gly-Tyr-NH }\end{array}$ & $\begin{array}{l}\text { Antagonista da adrenomedulina } \\
\text { (peptídeo hipotensor) }\end{array}$ & 8 \\
\hline Gomesina & $\begin{array}{l}\text { ciclo(2-15,6-11) } p \text {-Glu-Cys-Arg-Arg-Leu- } \\
\text { Cys-Tyr-Lys-Gln-Arg-Cys-Val-Thr-Tyr- } \\
\text { Cys-Arg-Gly-Arg-NH }\end{array}$ & Peptídeo antibiótico de amplo espectro de ação & 9 \\
\hline
\end{tabular}

*e-mail: mtmirand@iq.usp.br. 
micos, físicos, farmacológicos, bioquímicos e clínicos de grande parte dos peptídeos conhecidos. De fato, boa parte das fontes naturais é pobre nestes compostos, o que dificulta os isolamentos em quantidades suficientes à realização destes estudos. Os exemplos que se seguem ilustram tal escassez: i) para a obtenção de $5 \mathrm{mg}$ de somatostatina, hormônio envolvido no controle do metabolismo animal, são necessários 500.000 cérebros de carneiro ${ }^{11}$; ii) $12 \mathrm{~g}$ de medula adrenal originam 90 pmol de PAMP-12, peptídeo de 20 resíduos de aminoácidos com atividade hipotensiva ${ }^{12}$; iii) 3,4 $\mathrm{g}$ de pele seca do sapo marrom da montanha, $R$. ornativentris, fornecem $37 \mathrm{e}$ $580 \mathrm{nmol}$ dos peptídeos antimicrobianos brevinina-2Oa e brevinina$2 \mathrm{Ob}$, respectivamente ${ }^{13}$; iv) 6-10 caracóis marinhos Conus ventricosus fornecem aproximamente $5 \mathrm{mg}$ de veneno bruto contendo o nonapeptídeo "contryphan-Vn"14.

Os peptídeos sintéticos passaram a servir como provas inequívocas das identidades químicas e dos papéis biológicos dos peptídeos naturais. Além disto, de posse deles poder-se-ia construir curvaspadrões (concentração versus absorção ou emissão de luz ou desenvolvimento de coloração) que permitiriam quantificar os peptídeos correspondentes contidos em extratos brutos ou em frações obtidas durante os seus isolamentos ${ }^{15}$. Assim, métodos eficientes de síntese foram concebidos, estabelecidos e aprimorados. Conjuntamente, técnicas envolvendo a manipulação, síntese e clonagem de genes foram sendo desenvolvidas.

\section{MÉTODOS DE SÍNTESE DE PEPTÍDEOS}

Atualmente, três são os passíveis de serem empregados para a preparação destes compostos em número e escala variados: síntese química, síntese enzimática (ou biocatalisada) e síntese via DNA recombinante.

\section{Síntese química}

É assim denominada porque utiliza um reagente químico para ativar o ácido carboxílico de um $N^{\alpha}$-acil-aminoácido ou $N^{\alpha}$-acil-fragmento peptídico $(\mathrm{RCOOH}$, componente carboxílico, doador de acila ou agente acilante), o qual sofre o ataque nucleofílico do grupo $\alpha$ amino de outro aminoácido ou fragmento peptídico $C^{\alpha}$-bloqueados $\left(\mathrm{H}_{2} \mathrm{~N}-\mathrm{R}^{1}\right.$, componente amínico, receptor de acila ou agente nucleofílico) resultando na formação da ligação peptídica entre eles (RCONHR ${ }^{1}$, Esquema 1). Neste caso, os grupos funcionais reativos que não estão diretamente envolvidos na formação da ligação peptídica devem ser previamente protegidos ou bloqueados. Assim, a síntese torna-se mais controlada em relação à possível formação de subprodutos.

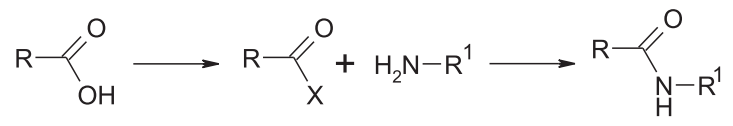

Esquema 1. Representação geral da formação de uma ligação amida

Em síntese de peptídeos, a formação de ligação amida entre dois aminoácidos ou fragmentos peptídicos é chamada de acoplamento. Existem três diferentes maneiras de promover esta reação: a) o componente carboxílico é ativado ( $\mathrm{RCOX}, \mathrm{X}=\mathrm{Cl}, \mathrm{N}_{3}, \mathrm{OCOR}$ ) e exposto ao componente amínico; b) o componente carboxílico ativado é isolado e purificado previamente à sua aminólise $(\mathrm{X}=\mathrm{OR}$; ésteres de pentafluorofenila, 2,4,5-triclorofenila, p-nitrofenila, p. ex.) e c) o agente acilante é gerado no meio reacional em presença do componente amínico, pela adição de um reagente ativador ou acoplador. Estes acopladores incluem etoxiacetileno, as carbodiimidas [DIC: $N, N^{\prime}-$ diisopropilcarbodiimida, DCC: $N, N$ '-dicicloexilcarbodiimida e EDC: 1-etil-3-(3-dimetilaminopropil)carbodiimida, p. ex.], sais de fosfônio [BOP: hexafluorofosfato de benzotriazol-1-il-oxi-tris-(dimetilamino)fosfônio e PyBOP: hexafluorofosfato de benzotriazol-1-il-oxitris(pirrolidino) fosfônio, p.ex.] e de urônio [TBTU: tetrafluoroborato de 2-(1-H-benzotriazol-1-il)-1,1,3,3-tetrametilurônio, HBTU: hexafluorofosfato de 2-(1-H-benzotriazol-1-il)-1,1,3,3-tetrametilurônio, HATU: hexafluorofosfato de 2-(1-H-7-azabenzotriazol-1-il)1,1,3,3-tetrametilurônio, PyAOP: hexafluorofosfato de 7azabenzotriazol-1-il-oxi-tris(pirrolidino) fosfônio, p. ex.] ${ }^{16}$.

A síntese química pode ocorrer em duas modalidades: em solução (síntese clássica) ou na presença de um suporte polimérico (síntese de peptídeos em fase sólida; SPFS). Na primeira, geralmente a $\alpha$-carboxila do receptor de acila é esterificada ou amidada. Na SPFS, este grupo liga-se covalentemente ao suporte polimérico ou resina. A síntese clássica pode ocorrer na direção $\mathrm{N} \rightarrow \mathrm{C}$-terminal ou viceversa, enquanto que a SPFS geralmente ocorre na direção do $\mathrm{C} \rightarrow \mathrm{N}$ terminal ${ }^{17}$.

O Esquema 2 resume as modalidades e estratégias químicas empregadas. As estratégias são determinadas pelos tipos de protetores dos grupos reativos dos aminoácidos envolvidos na síntese. De fato, a estratégia Boc emprega a $t$-butiloxicarbonila, lábil ao ácido trifluoroacético (TFA), para proteger o grupo $\alpha$-amino dos doadores de acila que têm as suas cadeias laterais reativas bloqueadas por grupos estáveis a este ácido e lábeis a ácidos inorgânicos fortes ou hidrogenólise. Estes protetores incluem a benziloxicarbonila, a benzila e a tosila. No caso da síntese em solução, as carboxilas Cterminais dos receptores de acila são geralmente esterificadas ou amidadas (estáveis ao TFA). Na SPFS, a estratégia química Boc utiliza suportes funcionalizados por "handles" ou "linkers" que estabelecem com a sequiência peptídica ligações estáveis à exposição ao TFA e lábeis a ácidos inorgânicos ${ }^{18}$.

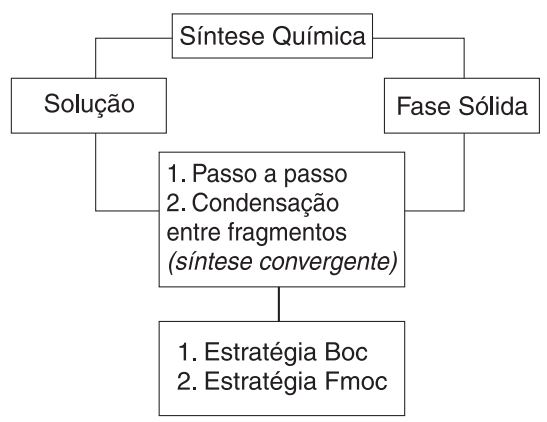

Esquema 2. Modalidades e estratégias da síntese química

A estratégia Fmoc emprega a 9-fluorenilmetoxicarbonila, estável ao TFA e lábil a bases orgânicas, como protetor do grupo $\alpha$ amino dos doadores de acila, que têm as suas cadeias laterais reativas protegidas por grupos estáveis à base empregada e lábeis ao TFA. Estes protetores de cadeia lateral incluem a $t$-butiloxicarbonila, o tritil e a $t$-butila. No caso da síntese em solução, as carboxilas C-terminais dos receptores de acila são geralmente esterificadas ou amidadas (estáveis à base e lábeis ao TFA). Na SPFS, a estratégia química Fmoc utiliza suportes funcionalizados por "handles" ou "linkers" que estabelecem com a sequiência peptídica ligações estáveis a bases orgânicas e lábeis ao TFA ${ }^{19}$.

A Tabela 2 exemplifica algumas das resinas empregadas na SPFS via estratégia Boc e Fmoc para obtenção de peptídeos de C-terminal ácido, éster ou amida. Esta modalidade é a mais empregada para a obtenção de peptídeos sintéticos, devido à sua praticidade, rapidez e possibilidade de automatização. Ela apresenta ainda outras possibi- 
Tabela 2. Exemplos de resinas empregadas em SPFS com o seu respectivo grupo funcional, que conecta o peptídeo ao suporte polimérico ${ }^{\circledR}$

\begin{tabular}{|c|c|c|}
\hline Resina & Condições de clivagem & C-terminal resultante \\
\hline Merrifield (cloreto de metilfenila) & $\mathrm{HF}$ & ácido \\
\hline PAM (ácido 4-hidroximetilfenilacético) & $\begin{array}{l}\text { HF, } \\
\text { TFMSA }^{\mathrm{a}} \\
\text { TMSOTf }^{\mathrm{b}}\end{array}$ & ácido \\
\hline KOR (oxima de 4-nitrobenzofenona) & $\begin{array}{c}\mathrm{HF} \\
\mathrm{HOPip}{ }^{\mathrm{c}}, \\
\mathrm{AA}^{-+} \mathrm{N}(n \mathrm{Bu})_{4}^{\mathrm{d}}, \\
\mathrm{H}_{2} \mathrm{~N}-\mathrm{CH}(\mathrm{R}) \mathrm{COX}^{\mathrm{e}} \\
\mathrm{H}_{2} \mathrm{~N} \text {-peptídeo-COX }{ }^{\mathrm{e}}\end{array}$ & $\begin{array}{l}\text { ácido } \\
\text { amida } \\
\text { éster }\end{array}$ \\
\hline SASRINTM (álcool 2-metoxi-4-alcoxibenzílico) & TFA diluído & ácido \\
\hline cloreto de 2-clorotritila & $\begin{array}{c}\text { TFA } \\
\mathrm{AcOH}\end{array}$ & ácido \\
\hline MBHA (4-metilbenzidrilamina) & $\begin{array}{c}\text { HF } \\
\text { TFMSA }^{\text {a }} \\
\text { TMSOTf }^{\mathrm{b}} \\
\text { HBr/TFA }\end{array}$ & amida \\
\hline
\end{tabular}

SAMBHA (4-succinilamino-2,2',4'-trimetoxibenzidrilamina)

TFA

amida<smiles>COc1ccc(C(C)N)c(OC)c1</smiles>

®: co-polímero de poliestireno e divinilbenzeno (1-2\%); ácido trifluorometanosulfônico, btrifluorometanosulfonato de trimetilsilila, ${ }^{\mathrm{c}} 1$ hidroxipiperidina, ${ }^{\mathrm{d}} \mathrm{AA}$ : aminoácido, ${ }^{\mathrm{e}} \mathrm{X}: \mathrm{NH}_{2}, \mathrm{OR}$.

lidades que estão apresentadas no Esquema 3: síntese individual, em paralelo ou múltipla ${ }^{20}$ (gera dezenas a milhares de peptídeos, que tem sua estrutura e localização definidas e podem ser confirmadas por técnicas analíticas) e síntese via química combinatória ou bibliotecas (que produz milhares a milhões de peptídeos) ${ }^{21}$.

A construção individual da cadeia peptídica em solução ou sobre uma fase sólida pode se dar passo a passo (aminoácido por aminoácido) ou por condensação entre fragmentos de cadeias laterais protegidas previamente sintetizados, purificados e caracterizados quimicamente (síntese convergente).
Independentemente da modalidade, estratégia química ou do fato de a síntese ser feita individual ou paralelamente, a etapa final do processo sintético via método químico refere-se à desproteção total da seqüência em meio ácido (remoção de todos os grupos protetores) para a produção do peptídeo bruto livre que deverá ser devidamente analisado, purificado e caracterizado quimicamente. No caso da SPFS, esta etapa ocorre simultaneamente à clivagem do peptídeo do suporte polimérico funcionalizado ${ }^{22}$.

A SPFS está bem estabelecida e, em princípio, é aplicável a qualquer seqüência. Por sua concepção, R. B. Merrifield foi agraciado 


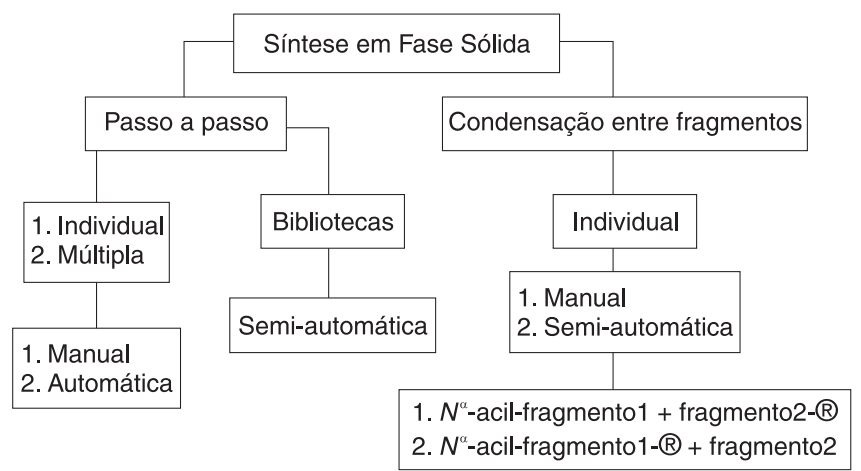

Esquema 3. Diferentes abordagens dentro da SPFS

com o Nobel de Química em 1984. Na realidade, entretanto, esta metodologia ainda apresenta vários problemas de difícil solução, tais como racemização dos doadores de acila quando na sua ativação e acoplamento, agregação das cadeias peptídicas em crescimento, inúmeras reações secundárias e baixos rendimentos de obtenção de determinados peptídeos longos (> 25-30 resíduos). Assim sendo, muitos laboratórios ao redor do mundo se dedicam à busca do aprimoramento e agilização desta metodologia sintética ${ }^{23}$ ou à sua adequação a determinadas seqüências ${ }^{24}$.

\section{Síntese enzimática ou biocatalisada}

Neste método a formação da ligação peptídica não mais é mediada por um reagente químico, mas sim por uma enzima em sua forma livre ou imobilizada ${ }^{25}$. Da mesma forma que a síntese química, esta também pode ser realizada passo a passo ou via condensação entre segmentos peptídicos preparados previamente ${ }^{26}$ (Esquema 4).

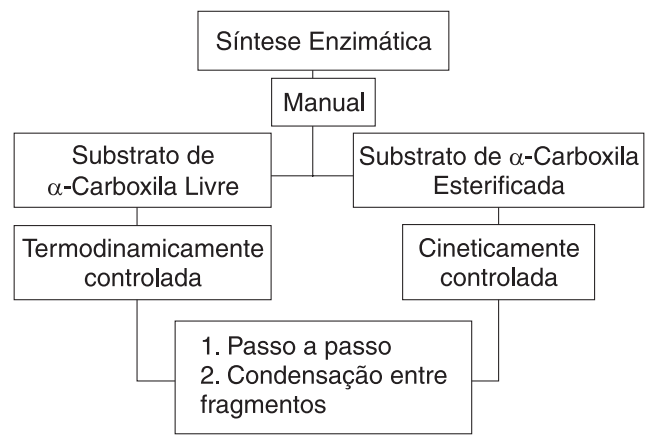

Esquema 4. Modalidades e estratégias da síntese enzimática

As proteases, enzimas responsáveis pela quebra da ligação peptídica in vivo, foram inicialmente eleitas como os catalisadores mais adequados. Dentre as mais utilizadas estão a termolisina ${ }^{27}$, a pepsina $^{28}$, a subtilisina ${ }^{29}$, a tripsina $a^{26,30,31}$, a $\alpha$-quimotripsina ${ }^{32}$, a papaína $^{33}$, a clostripaína ${ }^{34}$ e a carboxipeptidase- $Y^{35}$. Entretanto, a observação de que, simultaneamente à catálise da síntese de ligação peptídica, estas enzimas mediavam a hidrólise secundária do peptídeo formado ou dos fragmentos peptídicos reagentes ${ }^{36}$ levou à busca de outros biocatalisadores que exibem atividade esterásica sem apresentar atividade amidásica e, se possível, que também aceitem Daminoácidos e aminoácidos não usuais. Dentre eles estão as lipases, esterases que catalisam a hidrólise de triacilgliceróis in vivo com geração de mono e diglicerídeos, glicerol e ácidos graxos livres. As mais utilizadas têm sido a de pâncreas de porco $^{37-39}$, de Candida cilindracea $^{40}$ e a de Pseudomonas $s p .{ }^{41}$.

A síntese enzimática de peptídeos oferece vantagens em relação à química, tais como: i) elevada estereo- e regiosseletividade; ii) ausência de racemização e de outras reações secundárias típicas da síntese química; iii) proteção parcial dos substratos; iv) tolerância à presença de água nos meios reacionais; v) possibilidade de emprego de reatores para a produção em larga escala e vi) barateamento do processo. Por outro lado, o fato de não existir uma enzima universal faz com que a metodologia não seja geral ou aplicável a qualquer sequiência peptídica e que ainda continue a ser objeto de pesquisa e desenvolvimento ${ }^{38,42}$.

As abordagens experimentais exploradas para se conseguir a formação de uma ligação peptídica mediante catálise por uma enzima baseiam-se em simples inversão da reação de hidrólise, aminólise de amidas (também chamada de transpeptidação) e aminólise de ésteres. A inversão da hidrólise e a aminólise de amidas são reversíveis e, portanto, termodinamicamente controladas. A aminólise de ésteres é irreversível, podendo assim ser considerada cineticamente controlada ${ }^{43}$.

\section{Inversão da hidrólise da ligação peptídica}

Em solução aquosa a hidrólise da ligação peptídica processa-se em duas etapas distintas (Esquema 5): a formação de produtos não ionizados, endergônica $\left(\Delta \mathrm{G}_{\text {hid }}>0\right)$, e a etapa de ionização e solvatação destes produtos, exergônica $\left(\Delta \mathrm{G}_{\text {ion }}<0\right)$. Uma vez que nestas condições o valor do $\Delta \mathrm{G}_{\text {ion }}$ é maior do que o do $\Delta \mathrm{G}_{\text {hid }}$, a hidrólise da ligação peptídica é termodinamicamente favorecida.

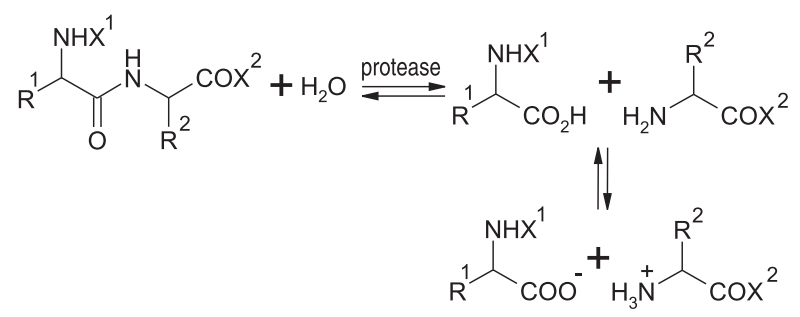

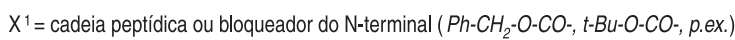

$\mathrm{X}^{2}=$ cadeia peptídica ou bloqueador do C-terminal ( $t-\mathrm{Bu}, \mathrm{Ph}-\mathrm{CH}_{2}-, \mathrm{Ph}-\mathrm{NH}-\mathrm{NH}-, \mathrm{p}$.ex. $)$

$\mathrm{R}^{1}, \mathrm{R}^{2}=$ cadeias laterais dos aminoácidos

Esquema 5. Síntese enzimática de peptídeos por inversão da hidrólise da ligação peptídica

Portanto, para promover a inversão da reação de hidrólise (síntese representada pela curva A da Figura 1) é necessário diminuir a barreira energética correspondente à etapa de ionização dos grupos

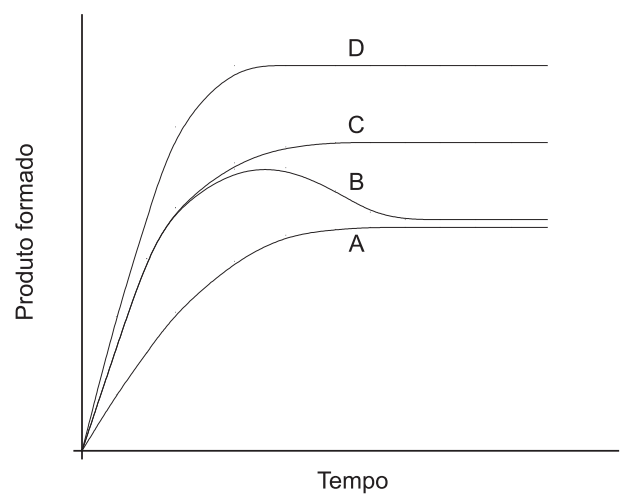

Figura 1. Síntese de peptídeos em condições termodinâmica e cineticamente controladas. (A) Síntese de peptídeos via inversão da reação de hidrólise ou por transpeptidação catalisada por proteases, $(B)$ síntese de peptídeos via aminólise de ésteres catalisada por proteases em meio contendo água, (C) síntese de peptídeos via aminólise de ésteres catalisada por lipases em meio contendo água e (D) síntese de peptídeos via aminólise de ésteres catalisada por lipases ou proteases em meio anidro 
$\alpha$-amino e carboxila dos substratos. Isto é conseguido por bloqueamento destes grupos, adição de solventes orgânicos ao meio reacional (ambos provocam a alteração dos valores de pKa dos grupos ionizáveis e, conseqüentemente, a diminuição do valor do $\Delta \mathrm{G}_{\text {ion }}$ ), uso de excesso de um dos substratos (deslocamento do equilíbrio da reação para o sentido de síntese pela lei de ação das massas) e/ou remoção do produto do meio reacional por precipitação, extração ou interação com um "trap" molecular específico. O emprego de altas porcentagens de solventes orgânicos leva à redução da possibilidade de hidrólise secundária dos reagentes ou do produto formado e, também, a alterações benéficas nas propriedades do biocatalisador (atividade, estabilidade e/ou especificidade) $)^{26,31,44}$.

\section{Transpeptidação}

$\mathrm{Na}$ transpeptidação (Esquema 6) ocorre a quebra da ligação peptídica existente, com formação do intermediário ativo acil-enzima. A presença de um nucleófilo (peptídeo ou aminoácido bloqueado em sua $\alpha$-carboxila) propicia o ataque a este intermediário e conseqüente formação da nova ligação peptídica ${ }^{45}$.
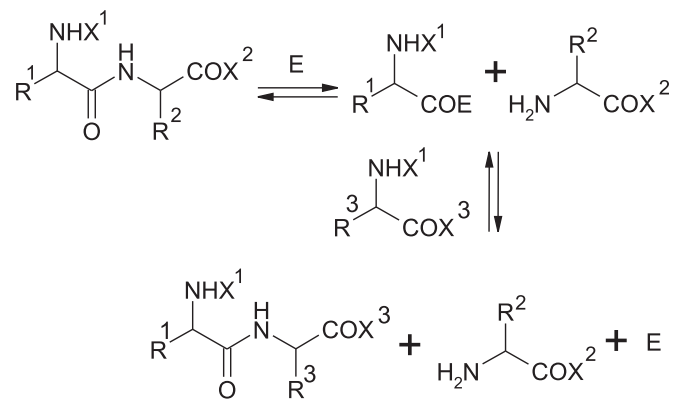

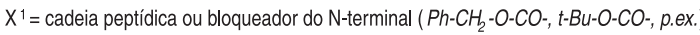

$\mathrm{X}^{2}, \mathrm{X}^{3}=$ cadeia peptídica ou bloqueador do C-terminal ( $t-\mathrm{Bu}, \mathrm{Ph}_{-} \mathrm{CH}_{2}-, \mathrm{Ph}-\mathrm{NH}-\mathrm{NH}-$, p.ex. $)$

$R^{1}, R^{2}, R^{3}=$ cadeias laterais dos aminoácidos

$E=$ protease

Esquema 6. Síntese enzimática de peptídeos por transpeptidação

Da mesma forma que na inversão da reação de hidrólise, para deslocar o equilíbrio da reação para o sentido da síntese é necessário recorrer a proteções dos grupos $\alpha$-amino e carboxila dos substratos, adicionar solventes orgânicos aos meios reacionais, usar excesso de um dos substratos e/ou promover a remoção dos produtos dos meios reacionais. O comportamento cinético de formação do produto também pode ser representado pela curva A da Figura 1.

Sempre que o meio contiver água também é possível gerar subprodutos resultantes de hidrólise da ligação amida dos substratos ou produto ${ }^{26}$.

\section{Aminólise de ésteres}

A hidrólise de um éster de aminoácido ou peptídeo protegido em seu grupo $\alpha$-amino e esterificado em sua $\alpha$-carboxila por uma esterase também ocorre em duas etapas (Esquema 7): a formação do intermediário ativo acil-enzima com liberação para o meio reacional do álcool correspondente e o ataque nucleofílico do intermediário pela água.

Como esta última consiste na etapa limitante do processo, podese promover a formação de uma ligação peptídica pela simples adição de um aminoácido ou peptídeo de $\alpha$-amino livre e C-terminal bloqueado ao meio reacional (componente amínico). De fato, nestas condições deverá ocorrer a competição entre a água e este novo nucleófilo pelo ataque ao intermediário acil-enzima ${ }^{46}$ (curva B e C da Figura 1). Assim, a natureza do éster empregado ${ }^{30}$, a nucleofilicidade e concentração do componente amínico são os fatores determinantes da reação de síntese ou de hidrólise em questão.
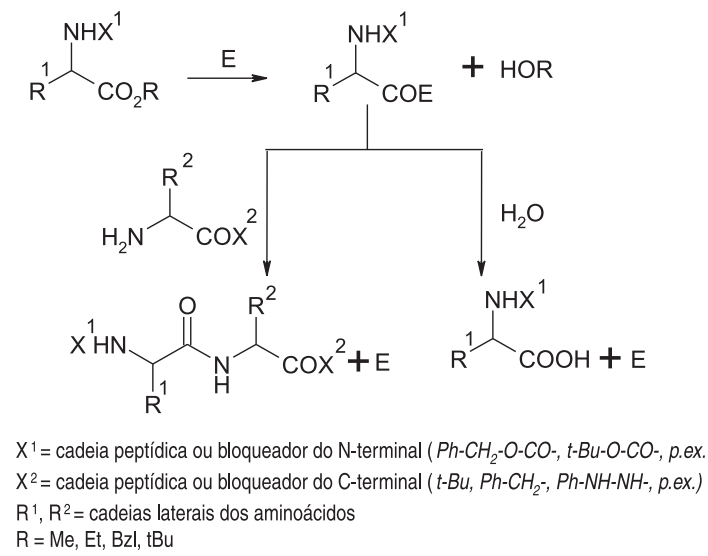

Esquema 7. Síntese enzimática de peptídeos por aminólise de ésteres

Sob o ponto de vista do catalisador, se for usada uma protease em meio reacional contendo água, poderão ocorrer a síntese da amida e as hidrólises do éster e/ou da própria ligação peptídica recém-formada (curva B da Figura 1). Se for utilizada uma esterase sem atividade amidásica em meio reacional aquo-orgânico, é possível ocorrer a síntese da ligação peptídica e a hidrólise do éster do componente carboxílico $^{43,39}$ (curva C da Figura 1).

Assim sendo, a formação da ligação peptídica segundo a aminólise de ésteres, estratégia cineticamente controlada (curvas B, $\mathrm{C}$ e D da Figura 1) é, em geral, mais rápida ${ }^{37}$ que segundo a inversão da hidrólise ou transpeptidação, estratégias termodinamicamente controladas (curva A da Figura 1) 26,27,30.

Pelo exposto acima fica evidente que o rendimento da reação da síntese enzimática de ligação peptídica é, em linhas gerais, fortemente influenciado pelos seguintes fatores: natureza da enzima, presença ou não de água, solvente orgânico empregado, tipos/concentrações/solubilidades dos substratos e tipo/solubilidade do produto. Por esta razão, para maximizar os rendimentos de síntese recomenda-se: i) escolher o biocatalisador baseando-se nas suas especificidades primária e secundária, a fim de assegurar sua maior interação com os substratos ${ }^{47}$; ii) empregar cosolventes orgânicos para alterar as propriedades dos substratos, diminuir a atividade amidásica de protease $^{48}$ e alterar as especificidades ou mesmo aumentar as atividades das enzimas ${ }^{49}$; iii) usar sistemas congelados (temperaturas de reação inferiores $\mathrm{a}-10{ }^{\circ} \mathrm{C}$ ) a fim de minimizar a atividade da água ${ }^{50}$; iv) utilizar substratos miméticos ${ }^{30,51} \mathrm{e}$ v) empregar lipases em meios bifásicos específicos propícios a estas enzimas e à ocorrência de síntese $\mathrm{s}^{37,38}$.

\section{Síntese via tecnologia do DNA recombinante}

Utiliza todos os métodos modernos de clonagem e expressão gênica via microorganismos modificados, podendo produzir um peptídeo recombinante ou vários deles simultaneamente. A grande maioria dos laboratórios utiliza bactérias como sistemas de expressão (seres procarióticos desprovidos do aparato biológico necessário à introdução de modificações pós-tradução nas sequiências peptídicas recém-produzidas) ${ }^{52}$. Outros empregam a técnica de "phage display" em que o peptídeo desejado é secretado, mas se mantém ligado ao organismo (fago) que o produz ${ }^{53}$. Em ambos os casos, são gerados peptídeos contendo apenas os aminoácidos proteinogênicos não modificados. Relativamente à síntese química, é ainda muito menos empregada para a preparação de peptídeos de até 40 resíduos de aminoácidos contendo modificações químicas (amidação, fosforilação, sulfatação, acetilação ou ciclização). 
Para finalizar é preciso lembrar que: 1) com a automatização da síntese em fase sólida ${ }^{18}$, a adaptação dos equipamentos para sínteses múltiplas, o desenvolvimento dos métodos para a química combinatória ${ }^{54} \mathrm{e}$ o aprimoramento das técnicas de biologia molecular ${ }^{55}$, os peptídeos sintéticos passaram a ser extensivamente produzidos e empregados como ferramenta de pesquisa em áreas variadas e 2) independentemente do método de síntese empregado, estes compostos são invariavelmente obtidos nas formas bruta ou precursora. Assim, obrigatoriamente eles devem ser manipulados, purificados e caracterizados quimica e biologicamente. Sem estas etapas, que permitem avaliar suas homogeneidades químicas, determinar suas concentrações efetivas e confirmar as suas identidades, os peptídeos deixam de ser materiais confiáveis para aqueles que pretendem estudá-los ou consumi-los.

Um outro ponto importante a ser mencionado é o fato de as sínteses em fase sólida e enzimática convergentes utilizarem como reagentes fragmentos peptídicos distintos. Para a SPFS convergente devem ser empregados fragmentos $N^{\alpha}$-acilados totalmente protegidos nas cadeias laterais reativas dos aminoácidos ${ }^{56}$ (Boc-Ser(Bzl)Pro-Glu(OBzl)-Ala, p. ex.). Já para a síntese enzimática convergente, estes devem ser $N^{\alpha}$-acilados e esterificados na $\alpha$-carboxila ${ }^{37}$ (BocSer-Pro-Glu-Ala-OMe, p. ex.). Os estudos que relatam sínteses destes compostos indicam que elas são bastante trabalhosas e que as metodologias empregadas não são igualmente eficientes para todas as seqüências. Assim, novas alternativas metodológicas têm sido buscadas. É o caso dos trabalhos de Moraes e colaboradores que prepararam segmentos peptídicos como os exemplificados acima via hidrólise ou alcoólise do éster de oxima formado entre a resina de Kaiser e os peptídeos correspondentes ${ }^{57}$.

\section{PURIFICAÇÃO DOS PEPTÍDEOS SINTÉTICOS}

Para uso clínico, consumo alimentar, realização de determinados testes biológicos e estudos estruturais ou que explorem a relação estrutura-atividade, são requeridos peptídeos com purezas iguais ou superiores a $95 \%$. Assim, tornou-se muito comum combinar técnicas cromatográficas de baixa, média e alta resolução para obter peptídeos sintéticos com esta qualidade.

As cromatografias líquidas de fase reversa, troca iônica, exclusão e de afinidade são as mais utilizadas na análise e purificação dos produtos brutos obtidos a partir das sínteses química e enzimática. Nas últimas décadas, a cromatografia líquida de fase reversa (RPHPLC) tornou-se a técnica preferida ${ }^{58}$.

A RP-HPLC baseia-se na adsorção dos peptídeos sintéticos a uma matriz estacionária hidrofóbica [sílica derivatizada pela introdução de cadeias alquílicas, tais como $n$-butila $\left(\mathrm{C}_{4}\right), n$-octila $\left(\mathrm{C}_{8}\right)$, $n$-octadecila $\left(\mathrm{C}_{18}\right)$, fenila, ciclohexila e outros $\left.{ }^{59}\right]$, bem como na partição destes solutos entre esta matriz e a fase móvel ou eluente. A fase móvel geralmente empregada é ácida e com baixa força iônica. São utilizados gradientes de dois eluentes: um deles é água acidulada com ácido trifluoroacético (TFA), fosfórico, perclórico, acético ou hepta-fluorobutírico (solvente A) e o outro é constituído por A e metanol, acetonitrila (ACN), 1- ou 2-propanol. O ácido utilizado determina o contra-íon do sal formado entre os grupos $\mathrm{NH}_{3}{ }^{+} \mathrm{do}(\mathrm{s})$ peptídeo(s), o que afeta a eluição dos componentes da amostra cromatografada. Para a detecção recomenda-se o uso dos seguintes comprimentos de onda: 210-225 ou 275-280 nm.

A purificação pode ser executada em escala preparativa (gramas) ou semipreparativa (100 mg de amostra bruta). A escala analítica (até $1 \mathrm{mg}$ de peptídeo bruto) é usada na definição das condições da escala preparativa e subseqüente análise das frações obtidas durante a purificação.

A Figura 2 mostra perfis cromatográficos de RP-HPLC obtidos em nosso laboratório em análises comparativas das formas bruta (A) e purificada (B) de um análogo sintético de um fragmento do fator de crescimento de fibroblastos humano. A purificação foi feita em escala semipreparativa com cortes manuais e monitoramento por RPHPLC analítica das frações obtidas ${ }^{60}$.

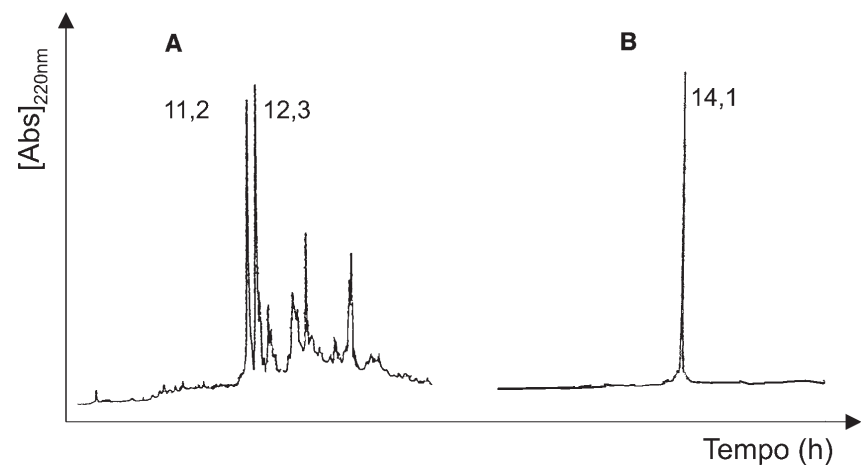

Figura 2. Perfis de RP-HPLC do peptídeo sintético ciclo(1-5)Ac-Asp-LysLys-His-Dbu-Glu-Lys-Asn-Trp-Phe-NH $\mathrm{H}_{2}$ bruto, $t_{r}=12,3 \mathrm{~min}$, (A) e dele purificado (B). Condições analíticas: coluna Vydac $C_{18}$; fluxo: $1 \mathrm{~mL} / \mathrm{min}$; solvente A: fosfato de trietilamina (TEAP), solvente B: $60 \%$ ACN/TEAP; gradientes lineares: 5-95\% de B em $30 \mathrm{~min}$ (A); 15-35\% de B em $20 \mathrm{~min}$ (B). Dbu: ácido diaminobutírico

É importante esclarecer que o monitoramento da purificação pode ser obtido via RP-HPLC acoplada à espectrometria de massas com ionização por "electrospray" (LC/ESI-MS) ${ }^{61}$. Neste caso, determina-se simultaneamente a qualidade e a identidade das diferentes frações.

\section{CARACTERIZAÇÃO DOS PEPTÍDEOS SINTÉTICOS PURIFICADOS}

Previamente à determinação da sua estrutura, o sintético purificado deve ser analisado quanto à sua homogeneidade química. Como já citado, o grau de pureza desejável depende do tipo de uso que o sintético terá. De fato, existem aplicações em que valores entre 75 e $85 \%$ são perfeitamente toleráveis e outras, em que não devem ser inferiores a $95 \%$.

Este tipo de avaliação é geralmente conseguida através de análises por cromatografia líquida de alta eficiência ${ }^{27,58}$ e eletroforese capilar $(\mathrm{CE})^{62}$. No primeiro caso, determina-se o tempo de retenção em condições analíticas variadas (diferentes gradientes empregando diferentes eluentes e/ou colunas). A mobilidade eletroforética é obtida por $\mathrm{CE}$, que funciona como método analítico complementar à RP-HPLC. Tanto o cromatógrafo líquido quanto o equipamento de CE podem estar acoplados a um espectrômetro de massas do tipo ESI-MS ${ }^{63,64}$. A comparação dos resultados encontrados nestas análises com aqueles dos sintéticos brutos indicam se a síntese/purificação foram bem sucedidas e o grau de confiabilidade do material sintético.

No caso do grau de pureza ter sido determinado apenas por RPHPLC e CE, o sintético a ser caracterizado deve obrigatoriamente ser analisado por diferentes tecnologias ou modalidades de espectrometria de massas: ESI-MS, "Fast Atom Bombardment Mass Spectrometry" (FAB-MS; ionização via bombardeamento rápido de átomos) e "Matrix-Assisted Laser Desorption/Ionization Mass Spectrometry" (MALDI-MS; ionização via dessorção por laser) ${ }^{65}$.

A determinação da composição de aminoácidos é de fundamental importância para a caracterização química de um sintético correspondente a um peptídeo biologicamente ativo, já que ela fornece o seu conteúdo peptídico. Este tipo de análise compreende duas etapas distintas: hidrólise total e análise do hidrolisado por RP-HPLC ou 
HPLC de troca iônica. A última consiste em separar/derivatizar ou derivatizar/separar os aminoácidos do hidrolisado para a sua detecção/ identificação. A ordem é definida pelo tipo de derivatização empregado: pré- ou pós-coluna ${ }^{58}$.

O seqüenciamento via degradação de $\operatorname{Edman}^{66}$ ou por espectrometria de massas com fragmentação (FAB-MS/MS e ESI$\mathrm{MS} / \mathrm{MS})^{67}$ é opcional, sendo, porém, altamente recomendável quando o peptídeo sintético é longo (> 25-30 resíduos).

A ressonância magnética nuclear (RMN) de alta resolução é outra técnica analítica importante para a caracterização dos peptídeos sintéticos. A ${ }^{1} \mathrm{H}-\mathrm{RMN}$ bidimensional é a mais empregada. Pode-se também utilizar as de ${ }^{13} \mathrm{C}$ e ${ }^{15} \mathrm{~N}$. O objetivo deste tipo de caracterização não é apenas a identificação estrutural, mas também a investigação do comportamento conformacional destas biomoléculas em solução, na ausência ou presença de receptores proteicos ou micelas. De fato, os avanços técnicos das últimas décadas viabilizaram a realização de experimentos que permitem identificar interações intramoleculares entre átomos unidos por ligação química ou simplesmente próximos, devido a uma organização molecular tridimensional ${ }^{68}$.

\section{EXEMPLOS DE APLICAÇÃO DOS PEPTÍDEOS SINTÉTICOS PURIFICADOS E CARACTERIZADOS}

Um número incontável de peptídeos biologicamente ativos foi sintetizado nos últimos cinqüenta anos. Parcela majoritária refere-se a sintéticos obtidos pelos métodos químico (em solução ou em fase sólida), enzimático ou combinação de ambos (semi-síntese) com vistas à realização de pesquisa científica em diferentes áreas ${ }^{69}$, ao uso terapêutico, alimentar, à produção de vacinas ou, ainda, como blocos construtivos de outras moléculas com ação biológica ${ }^{70}$.

$\mathrm{Na}$ impossibilidade de detalhar todas as possíveis aplicações, comentamos abaixo alguns exemplos.

\section{Identificação e quantificação de peptídeos biologicamente ativos conhecidos}

Os peptídeos de estruturas conhecidas podem ser detectados e quantificados via HPLC ou CE em amostras provenientes de animais, plantas e microorganismos ou, ainda, em misturas brutas resultantes do processo sintético. Ambas as técnicas analíticas demandam o uso de padrões (geralmente peptídeos sintéticos) caracterizados química e biologicamente ${ }^{71}$. De fato, peptídeos idênticos apresentam as mesmas propriedades químicas, físicas e biológicas e, como consequiência, comportamentos cromatográficos e eletroforéticos idênticos.

\section{Exploração da relação entre a estrutura e a atividade biológica de peptídeos}

Os peptídeos podem ser rapidamente hidrolisados em presença das proteases presentes em nosso organismo. Por esta razão, é que eles podem apresentar baixa atividade oral e plasmática. Outras características relacionadas à dificuldade de transporte, excreção rápida pelo fígado ou rins e baixa seletividade podem também dificultar sua utilização em terapêutica ${ }^{72}$.

Este conhecimento tem impulsionado a realização de estudos que através de deleção, adição e modificação racional da sequiência de aminoácidos, grupos ionizáveis e/ou esqueleto peptídico visam desenvolver análogos de peptídeos biologicamente ativos com propriedades físicas e químicas capazes de agonizar ou antagonizar as suas ações, aumentar ou diminuir as suas potências e alterar as suas estabilidades frente a proteases e/ou seletividades. Este tipo de estudo é chamado de exploração da relação-estrutura atividade (SAR) e depende exclusivamente da síntese de peptídeos. Muitas vezes, en- tretanto, o estudo de SAR de um peptídeo biologicamente ativo tem como único objetivo elucidar o modo de ação do mesmo.

Em linhas gerais, os análogos sintéticos são inicialmente obtidos para determinar a contribuição individual de cada um dos aminoácidos da sequiência natural na expressão da atividade biológica. Em etapa posterior, eles definem como as cadeias laterais essenciais à atividade devem estar dispostas espacialmente ${ }^{73}$. O ponto final é a obtenção, mediante sínteses individuais e paralelas ou pela química combinatória, de estruturas parcial ou totalmente isentas de esqueleto peptídico (peptidomiméticos), que possam ser usadas como drogas ${ }^{74}$.

A exploração de SAR de vários hormônios peptídicos tem gerado compostos comerciais utilizados em terapêutica ${ }^{75}$. Recentemente, também os peptídeos antimicrobianos passaram a ser estudados usando esta abordagem ${ }^{76,77}$.

\section{Terapêutica}

Atualmente, os peptídeos sintéticos usados para fins terapêuticos movimentam 13 bilhões de dólares em um mercado que cresce $10 \%$ ao ano ${ }^{69}$. O hormônio ocitocina, primeiro peptídeo biologicamente ativo sintetizado quimicamente a ser comercializado, ocupa posição de destaque por ser o princípio ativo de medicamentos empregados no controle do trabalho de parto $^{78}$. Os análogos do fator liberador do hormônio luteinizante (LHRH) com ação agonista ou antagonista (leuprolide, goserelina e cetrorelix) têm sido usados no tratamento de determinados tipos de câncer hormônio-dependentes ${ }^{79}$. Os inibidores da enzima conversora de angiotensina (ACE, envolvida na produção do hormônio hipertensor angiotensina) enalapril e lisinopril vêm sendo empregados para a produção dos anti-hipertensores Zestril e Prinivil ${ }^{69}$. Até há poucos anos atrás, a insulina humana semi-sintética, obtida através da transpeptidação enzimática da insulina de porco ${ }^{80}$, era empregada no tratamento de diabetes tipo I.

Na última década, os sintéticos correspondentes a peptídeos antimicrobianos $^{81}$ e conotoxinas ${ }^{82}$ naturais também têm sido testados, devido ao seu enorme potencial em auxiliar no tratamento de determinadas infecções, doenças parasitárias e regeneração de feridas, bem como reduzir tumores.

\section{Desenvolvimento, aprimoramento e aplicabilidade de métodos analíticos}

Grande parte das tecnologias atuais de separação, análise, quantificação e identificação de peptídeos foram estabelecidas empregando peptídeos sintéticos de seqüências, tamanhos e estabilidades químicas variadas. Dentre elas estão as cromatografias líquidas de alta e média eficiências (HPLC e FPLC, respectivamente), a eletroforese capilar (CE), a espectrometria de massas (MS) e seu acoplamento com a HPLC e/ou CE e, finalmente, as ${ }^{1} \mathrm{H}-\mathrm{e}{ }^{13} \mathrm{C}-\mathrm{RMN}$ de alta resolução.

Invariavelmente, os estudos realizados objetivavam agilização, adequação e/ou aumento de eficiência, praticidade e aplicabilidade destes métodos. Como exemplos podem-se citar: i) estudos de efeitos de diferentes tampões na eficiência de purificação por RP-HPLC e análise por CE de peptídeos sintéticos brutos ${ }^{83}$; ii) obtenção de equações matemáticas para prever condições ótimas de separação, por HPLC e CE, de misturas complexas de peptídeos ${ }^{71}$; iii) estudos do processamento de neuropeptídeos sintéticos administrados por via intravenosa ou adicionados a amostras de plasma humano, usando ESI-MS ${ }^{84}$; iv) estudos de separação por MALDI-MS e ESI-MS entre fosfopeptídeos e seus correspondentes não fosforilados ${ }^{85}$; v) uso de hormônios peptídicos comerciais para estabelecer condições analíticas de separação e identificação por LC/ESI-MS de amostras brutas biológicas ou oriundas de sínteses ${ }^{86}$ e vi) estudo empregando 
dipeptídeos e angiotensina II sintéticos, com vistas a estabelecer metodologia alternativa de análise de peptídeos precariamente detectáveis pelas técnicas convencionais ${ }^{87}$.

Particularmente interessante é o exemplo da adequação do teste ELISA ("Enzyme-Linked Immunosorbent Assay"), baseado na interação antígeno-anticorpo, para a detecção do vírus da anemia infecciosa eqüina, em amostras de soros coletados em áreas endêmicas. Esta primeira tentativa de obtenção de um "kit" diagnóstico só foi possível graças ao uso de peptídeos sintéticos derivados de proteínas superficiais do vírus ${ }^{88}$.

\section{Imunologia}

Nas décadas passadas, os peptídeos sintéticos foram amplamente usados como imunógenos e na preparação de "kits" de diagnósti$\cos ^{89}$ mas, nos últimos anos, surgiu o interesse em tentar controlar alergias, doenças infecciosas e crescimento de determinados tumores através de vacinas constituídas por estas biomoléculas. É o caso do sarampo ${ }^{90}$, da malária ${ }^{91}$, da infecção causada pelo vírus sincitial respiratório humano ${ }^{92}$ e de melanoma ${ }^{93}$.

Os sintéticos empregados como candidatos potenciais de vacinas geralmente correspondem a fragmentos derivados de epitopos de proteínas antigênicas específicas ${ }^{94}$, a peptídeos que induzem resposta imune in vitro e in vivo frente a carboidratos ou, ainda, a peptídeos ramificados compostos de um esqueleto de lisinas ou de $\beta$-Ala-Lys, em cujos grupos $\varepsilon$-amino se ligam fragmentos de epitopos de proteínas antigênicas específicas (MAPs - "multiple antigenic peptide")

\section{CONCLUSÃO}

As sínteses química e enzimática são ferramentas essenciais na obtenção de peptídeos. A primeira, bem estabelecida e mais geral, é susceptível à racemização. A outra, ainda pouco explorada e mais específica, é enantiosseletiva. Ambas apresentam vantagens e problemas a serem solucionados. Invariavelmente, os sintéticos produzidos necessitam ser analisados, purificados e caracterizados quimicamente. Uma vez purificados, podem ser usados com diferentes propósitos, os quais se enquadram em diferentes áreas da ciência e no nosso cotidiano.

\section{AGRADECIMENTOS}

Os autores agradecem a FAPESP e o CNPq pelo apoio financeiro à pesquisa no Laboratório de Química de Peptídeos do IQ-USP e pelas bolsas concedidas a A. Machado, P. B. Proti e C. Remuzgo.

\section{REFERÊNCIAS}

1. Gutte, B.; Peptides: Synthesis, Structure, and Applications, Academic Press: New York, 1995.

2. Miranda, M. T. M.; Tese de Livre Docência, Universidade de São Paulo, Brasil, 2000.

3. Luscher, T. F.; Barton, M.; Circulation 2000, 102, 2434.

4. Ko, L.; Ann. Thorac. Surg. 2002, 73, 1185.

5. Arakama, M.; Nakatani, A.; Minohara, A.; Nakamura, M.; Biochem. J. 1967, 104, 900; Schreier, S.; Casallanovo, F.; Barbosa, S. R.; Vieira, R. F. F.; Cilli, E. M.; Paiva, T. B.; Paiva, A. C. M.; Nakaie, C. R.; Biophys. J. 2002, 82, 1538; Kanashiro, C. A.; Paiva, T. B.; Paiva, A. C. M.; Prioste, R. N.; Aboulafia, J.; Shimuta, S. I.; J. Pharmacol. Exp. Ther. 1995, 275, 1543.

6. Brazeau, P.; Vale, W.; Burgus, R.; Ling, N.; Butcher, M.; Rivier, J.; Guillemin, R.; Science 1973, 179, 77.

7. Eguchi, S.; Hirata, Y.; Iwasaki, H.; Sato, K.; Watanabe, T. X.; Inui, T.; Nakajima, K.; Sakakibara, S.; Marumo, F.; Endocrinology 1994, 135, 2454.

8. Bensch, K.W.; Raida, M.; Mägert, H.-J.; Schulz-Knappe, P.; Forssman, W.G.; FEBS Lett. 1995, 368, 331.
9. Silva Jr., P. I.; Daffre, S.; Bulet, P.; J. Biol. Chem. 2000, 275, 33464.

10. Kutsky, R. J.; Handbook of vitamins and hormones, Van Nostrand Reinhold Company: New York, 1973.

11. Francino, A. C. S.; Engenharia 1986, 456, 18.

12. Kuwasako, K.; Kitamura, K.; Ishiyama, Y.; Washimire, H.; Kato, J.; Kangawa, K.; Eto, T.; FEBS Lett. 1997, 414, 105.

13. Kim, J. B.; Colon, J. M.; Iwamuro, S.; Knoop, F. C.; J. Pept. Res. 2001, 58,349 .

14. Massilia, G. R.; Schinina, M. E.; Ascenzi, P.; Polticelli, F.; Biochem. Biophys. Res. Commun. 2001, 288, 908.

15. Glada, M. L. R.; Miranda, M. T. M.; Marquez, U. M. L.; Food Chem. 1998, $61,177$.

16. Pannneman, H. J.; Marx, A. F.; Arens, J. F.; Recl. Trav. Chim. Pays Bas 1959, 78, 487; Sarantakis, D.; Teichman, J.; Lien, E. L.; Fenchel, R.; Biochem. Biophys. Res. Commun. 1976, 336, 1976; Izdebski, J.; Pachulska, M.; Orlowska, A.; Int. J. Pept. Protein Res. 1994, 44, 414; Gibson, F. S.; Park, M. S.; Rapoport, H.; J. Org. Chem. 1995, 60, 3561; Castro, B.; Dormoy, J. R.; Evin, G.; Selve, C.; Tetrahedron Lett. 1975, 1219; Carpino, L.; El-Fahan, A.; Minor, C. A.; Albericio, F.; J. Chem. Soc. Chem. Commun. 1994, 201; Dourtoglou, V.; Ziegler, J.-C.; Gross, B.; Tetrahedron Lett. 1978, 1269; Dourtoglou, V.; Gross, B.; Lambropoulou, V.; Zioudrou, C.; Synthesis 1984, 572; Knorr, R.; Trzeciak, A.; Bannwarth, W.; Gillessen, D.; Tetrahedron Lett. 1989, 30, 1927; Carpino, L.; El-Faham, A.; Albericio, F.; Tetrahedron Lett. 1994, 35, 2279.

17. Finn, F. M.; Hofmann, K. Em The Proteins; $3^{\text {rd }}$ ed., Neurath, H.; Hill, R. L., eds.; Academic Press: New York, 1976, vol. 2, p. 10; Sakakibara, S.; Biopolymers 1995, 37, 17; Kiso, H.; Yajima, H. Em ref. 1, p. 40; Barany, G.; Merrifield, R. B. Em The Peptides: Analysis, Synthesis, Biology, Part A, Gross, E.; Meienhofer, J., eds.; Academic Press: New York, 1979, vol. 2, p. 1.

18. Stewart, J. M.; Young, J. D.; Solid Phase Peptide Synthesis, $2^{\text {nd }}$ ed.; Pierce Chemical Company Rockford: Illinois, 1984.

19. Fields, G. B.; Noble, R. L.; Int. J. Pept. Protein Res. 1990, 35, 161.

20. Gorman, J. J.; Anal. Biochem. 1984, 136, 397; Krchnak, V.; Vagner. J.; Pept. Res. 1990, 3, 182; Gausepohl, H.; Boulin, C.; Kraft, M.; Frank, R. W.; Pept. Res. 1992, 5, 315; Luu, T.; Pham, S.; Deshpande, S.; Int. J. Pept. Protein Res. 1996, 91, 47.

21. Geysen, H. M.; Barteling, S. J.; Meloen, R. H.; Proc. Natl. Acad. Sci. U. S. A. 1985, 82, 178; Geysen, H. M.; Mason, T. J.; Bioorg. Med. Chem. Lett. 1993, 3, 397.

22. Bodanszky, M.; Peptide Chemistry: A Practical Textbook, $2^{\text {nd }}$ ed., SpringerVerlag Berlin: Heidelberg, 1993.

23. Varanda, L. M.; Miranda, M. T. M.; J. Pept. Res. 1997, 50, 102; Rivier, J.; Miranda, M. T. M.; Em Synthesis of Peptides and Peptido-mimetics; Goodman, M., ed.; Georg Thieme Verlag Stuttgart: New York, 2001, p. 806; Malavolta, L.; Oliveira, E.; Cilli, E. M.; Nakaie, C. R.; Tetrahedron 2002, 58, 4383; Cilli, E. M.; Oliveira, E.; Marchetto, R.; Nakaie, C. R.; J. Org. Chem. 1996, 61, 8992.

24. Kitagawa, K.; Aida, C.; Fujiwara, H.; Yagami, T.; Futaki, S.; Kogire, M.; Ida, J.; Inoue, K.; J. Org. Chem. 2001, 66, 1.

25. Faber, K.; Biotransformations in Organic Chemistry: A Textbook, $3^{\text {rd }}$ ed., Springer-Verlag Berlin: Heidelberg, 1997, p. 331.

26. Bemquerer, M. P.; Liria, C. W.; Kitagawa, K.; Miranda, M. T. M.; Tominaga, M.; J. Pept. Res. 1998, 51, 29.

27. Miranda, M. T. M.; Tominaga, M.; Int. J. Pept. Protein Res. 1991, 37, 128; Miranda, M. T. M.; Theobaldo, F. C.; Tominaga, M.; Int. J. Peptide Protein Res. 1991, 37, 451; Persichetti, R. A.; Stclair, N. L.; Griffith, J. P.; Navia, M. A.; Margolin, A. L.; J. Am. Chem. Soc. 1995, 117, 2732.

28. Bemquerer, M. P.; Adlercreutz, P.; Tominaga, M.; Int. J. Pep. Protein Res. 1994, 44, 448.

29. Moree, W. J.; Sears, P.; Kawashiro, K.; Witte, K.; Wong, C. H.; J. Am. Chem. Soc. 1997, 119, 3942.

30. Ivanov, I. P.; Yomtova, V. M.; Petkov, D. D.; Biocatal. Biotransform. 1997, 14, 195.

31. Liria, C. W.; Bemquerer, M. P.; Miranda, M. T. M.; Tetrahedron Lett. 1998, $39,4207$.

32. Cheng, E.; Miranda, M. T. M.; Tominaga, M.; Int. J. Pep. Protein Res. 1988, 31,116

33. Fite, M.; Álvaro, G.; Clapes, P.; Lopez-Santin, J.; Benaiges, M. D.; Caminal, G.; Enzyme Microb. Technol. 1998, 23, 199.

34. Bordusa, F.; Dahl, C.; Jakubke, H. D.; Burger, K.; Koksch, B.; Tetrahedron: Asymmetry 1999, 10, 307.

35. Kunugi, S.; Yanagi, Y.; Kitayaki, M.; Tanaka, N.; UeharaKunugi, Y.; $B$. Chem. Soc. Jpn. 1997, 70, 1459.

36. Xu, S.; Rall, K.; Bordusa, F.; J. Org. Chem. 2001, 66, 1627.

37. Liria, C. W.; Miranda, M. T. M. Em Peptides 2000; Martinez, J.; Fehrents, J.-A., eds.; EDK: Paris, 2001, p. 331. 
38. Liria, C. W.; Bordusa, F.; Miranda, M. T. M. Em Peptides 2002; Benedetti, E.; Pedone, C., eds.; Edizioni Ziino: Napoli, 2002, p. 222; Liria, C. W.; Miranda, M. T. M.; trabalho não publicado.

39. Zhang; L. Q.; Zhang; Y. D.; Xu, L.; Li, X. L.; Yang, X. C.; Xu, G. L.; Wu X. X.; Gao, H. Y.; Du, W. B.; Zhang, X. T.; Zhang, X. Z.; Enzyme Microb. Technol. 2001, 29, 129.

40. West, J. B.; Wong, C. H.; Tetrahedron Lett. 1987, 28, 1629; Matos, J. R.; West, J. B.; Wong, C.-H.; Biotechnol. Lett. 1987, 9, 233.

41. Kitaguchi, H.; Tai, D.-F.; Klibanov, A. M.; Tetrahedron Lett. 1998, 29, 5487.

42. Bordusa, F.; Chem. Rev. 2002, 102, 4817.

43. Kitaguchi, H. Em Enzymatic Reactions in Organic Media, Koskinen, A. M. P.; Klibanov, A. M., eds.; Blackie Academic \& Professional: London, 1996, p. 224.

44. Liu, P.; Tian, G. L.; Lee, K. S.; Wong, M. S.; Ye, Y. H.; Tetrahedron Lett. 2002, 43, 2423.

45. Schellenberger, V.; Jakubke, H.-D.; Angew. Chem., Int. Ed. 1991, 30, 1437.

46. Miyazawa, T.; Hiramatsu, M.; Murashima, T.; Yamada, T.; Biotechnol. Lett. 2002, 23, 1945.

47. Kullmann, W.; Enzimatic Peptide Synthesis, CRC Press Inc: Boca Raton, 1987 , p. 140

48. Barbas, C. F.; Matos, J. R.; West, J. B.; Wong, C. H.; J. Am. Chem. Soc. 1998, 110, 5162.

49. Lima, A. W. O.; Angnes, L.; Quim. Nova 1999, 22, 229.

50. Wehofsky, N.; Kirbach, S. W.; Haensler, M.; Wissmann, J. D.; Bordusa, F.; Org. Lett. 2000, 14, 2027.

51. Bordusa, F.; Curr. Protein Pept. Sci. 2002, 2, 159; Sekizaki, H.; Itoh, K.; Toyota, E.; Tanizawa, K.; J. Pept. Sci. 2002, 9, 521.

52. Harrison, S. J.; Mcmanus, A. M.; Marcus, J. P.; Goulter, K. Y.; Green, J. L.; Nielsen, K. J.; Craik, D. J.; Maclean, D. J.; Manners, J. M.; Protein Expression Purif. 1999, 15, 171; Kim, S. H.; Park, B. S.; Yun, E. Y.; Je, Y. H.; Woo, S. D.; Kang, S. K.; Biochem. Biophys. Res. Commun. 1998, 246, 388.

53. Smith, G. P.; Science 1985, 228, 1315.

54. Lebl, M.; Krchnák, V. Em Methods in Enzymology; Fields, G. B., ed.; Academic Press: San Diego, 1999, vol. 289, p. 336.

55. Pero, S. C.; Oligino, L.; Daly, R. J.; Soden, A. L.; Liu, C.; Roller, P. P.; Li, P.; Krag, D. N.; J. Biol. Chem. 2002, 277, 11918.

56. Benz, H.; Synthesis 1994, 337.

57. Moraes, C. M.; Bemquerer, M. P.; Miranda, M. T. M.; J. Pept. Res. 2000, 55, 279; Moraes, C. M.; Vieira, L. A. O.; Silva, K. N.; Miranda, M. T. M.; Em Peptides 2000, Proceedings of the $26^{\text {th }}$ European Peptide Symposium; Martinez, J.; Fehrentz, J.-A., eds.; EDK: Paris, 2001, p. 255.

58. Mant, C. T.; Hodges, R. S.; High-performance Liquid Chromatography of Peptides and Proteins: Separation, Analysis and Conformation, CRC Press Inc.: Boca Raton, 1991.

59. Esser, U.; Unger, K. K. Em ref. 58, p. 273.

60. Kiyota, S.; Tese de Doutorado, Universidade de São Paulo, Brasil, 2000; Kiyota, S.; Franzoni, L.; Nicastro, G.; Benedetti, A.; Oyama, S.; Viviani, W.; Gambarini, A. G.; Spisni, A.; Miranda, M. T. M.; J. Med. Chem. 2003, 46, 2325.

61. Cavelier, F.; Enjalbal, C.; El Haddadi, M.; Martinez, J.; Sanchez, P.; Verducci, J.; Aubagnac, J.-L.; Rapid Commun. Mass Spectrom. 1998, 12, 1585.

62. Miller, C.; Rivier, J.; Biopolymers 1996, 40, 265.

63. Mehlis, B.; Kertscher, U.; Anal. Chim. Acta 1997, 352, 71.

64. Serwe, M.; Ross, G.; Chromatographia 1999, 49, S73.

65. Alomirah, H. F.; Alli, I.; Konishi, Y.; J. Chromatogr., A 2000, 893, 1; Siuzdak, G.; Mass Spectrometry for Biotechnology, Academic Press: San Diego, 1996.

66. Powell, M.; Tempst, P.; Anal. Chem. 2001, 4, 776; Liu, Y.; Liang, S. P.; J. Protein Chem. 2001, 20, 535.

67. Griffiths, W. J.; Jonsson, A. P.; Lui, S. Y.; Rai, D. K.; Wang, Y. Q.; Biochem. J. 2001, 355, 545.
68. Huhmer, A. F. R.; Aced, G. I.; Perkins, M. D.; Gursoy, R. N.; Jois, D. S. S.; Larive, C.; Siahaan, T. J.; Schoneich, C.; Anal. Chem. 1997, 69, 29; Franzoni, L.; Nicastro, G.; Pertinhez, T. A.; Oliveira, E.; Nakaie, C. R.; Paiva, A. C. M.; Schreier, S.; Spisni, A.; J. Biol. Chem. 1999, 274, 227.

69. Verlander, M.; Chim. Oggi 2002, 7-8, 62.

70. Knaup, G.; Müller, T.; Schwarm, M.; Chim. Oggi 2003, 6, 49.

71. Sanz-Nebot, V.; Benavente, F.; Toro, I.; Barbosa, J.; J. Chromatogr., A 2003, 985, 411.

72. Veber, D. F.; Freidinger, R. M.; Trends. Neurosci. 1985, 8, 392; Rudinger, J. Em Drug Design; Ariëns, E. J., ed.; Academic Press: New York, 1971, vol. II, p. 119

73. Gante, J.; Angew. Chem., Int. Ed. 1994, 33, 1699; Hernandez, J. F.; Kornreich, W.; Rivier, C.; Miranda, A.; Yamamoto, G.; Andrews, J.; Tache, Y.; Vale, W.; Rivier, J.; J. Med. Chem. 1993, 36, 2860.

74. Günther, J.; Beck-Sickinger, A. G.; Angew. Chem., Int. Ed. 1992, 31, 367.

75. Adang, A. E. P.; Hermkens, P. H. H.; Linders, J. T. M.; Ottenheijm, H. C. J.; Vanstaveren, C. J.; Recl. Trav. Chim. Pays Bas 1994, 113, 63.

76. Fázio, M. A.; Daffre, S.; Miranda, M. T. M.; Bulet, P.; Miranda, A. Em Peptides: The Wave of the Future; Lebl, M.; Houghten, R. A., eds.; American Peptide Society: San Diego, 2001, p. 495; Machado, A.; Miranda, A.; Daffre, S.; Fázio, M. A.; Miranda, M. T. M. Em ref. 38, p. 224; Fázio, M. A.; Machado, A.; Daffre, S.; Miranda, M. T. M.; Miranda, A. Em ref. 38, p. 368.

77. Machado, A.; Sforça, M. L.; Daffre, S.; Miranda, A.; Spisni, A.; Pertinhez, T. A.; Miranda, M. T. M. Em Peptide Revolution: Genomics, Proteomics \& Therapeutics; Chorev, M.; Sawyer, T. K., eds.; American Peptide Society: San Diego, submetido.

78. Boissonnas, R. A.; Guttmann, St.; Jaquenoud, P.-A.; Waller, J.-P.; Helv. Chim. Acta. 1955, 38, 1491.

79. Schally, A. V.; Peptides 1999, 20, 1247.

80. Morihara, K.; Oka, T.; Tsuzuki, H.; Nature 1979, 280, 412.

81. Cudic, M.; Otvos, L.; Curr. Drug Targets: Infect. Disord. 2002, 3, 101.

82. Olivera, B. M.; Mol. Biol. Cell 1997, 8, 2101; Marí, F.; Fields, G. B.; Chim. Oggi 2003, 6, 43.

83. Hoeger, C.; Galyean, R.; Boublik, J.; McClintock, R.; Rivier, J.; Biochromatography 1987, 2, 134; Grossman, P. D.; Wilson, K. J.; Petrie, G.; Lauer, H. H.; Anal. Biochem. 1988, 173, 265; Grossman, P. D.; Colburn, J. C.; Lauer, H. H.; Anal. Biochem. 1989, 179, 28.

84. Chou, J. Z.; Kreek, M. J.; Chait, B. T.; J. Am. Soc. Mass Spectr. 1993, 5, 10.

85. Moyer, S. C.; Cotter, R. J.; Woods, A. S.; J. Am. Soc. Mass Spectr. 2002, $13,274$.

86. Toro, I.; Sanz-Nebot, V.; Barbosa, J.; J. Chromatogr., A 2000, 893, 95.

87. Rose, M. J.; Lunte, S. M.; Carlson, R. G.; Stobaugh, F.; J. Pharm. Biomed. Anal. 2003, 30, 1851.

88. Soutullo, A.; Verwimp, V.; Riveros, M.; Pauli, R.; Tonarelli, G.; Vet. Microbiol. 2001, 79, 111.

89. Yang, Y. P.; Liu, C. B.; Jin, D. Y.; Zhan, M. Y.; Tang, Q.; Xia, N. S.; Cao, J. Y.; Li, J. Y.; Sci. China Ser. B 1994, 37, 190; Chong, P.; Gillam, S.; Ou, D.; Tingle, A.; US pat. 6,180,758 1997; Goldstein, A. L.; Wang, Su-S.; US pat. 5,665,536 1997.

90. Pütz, M. M.; Hoebeke, J.; Ammerlaan, W.; Serge, S.; Muller C. P.; Eur. J. Biochem. 2003, 270, 1515.

91. Cubillos, M.; Salazar, L. M.; Libardo, T.; Patarroyo, M. E.; Biochimie 2003, 84, 1181.

92. Klinguer-Hamour, C.; Bussat, M.-C.; Plotnicky, H.; Velin, D.; Corvaia, N.; Nguyen, T.; Beck, A.; J. Peptide Res. 2003, 62, 27.

93. Bellone, M.; Iezzi, G.; Imro, M. A.; Protti, M. P.; Immunol. Today 1999, $20,457$.

94. Wang, C. Y.; Walfield, A. M.; Fang, X.; Hammerberg, B.; Ye, J.; Li, M. L.; Shen, F.; Shen, M.; Alexander, V.; MacGlashan, D. W.; Vaccine 2003, 21,1580 .

95. Tam, J. P. Em ref. 1, p. 455; Haro, I.; Perez, S.; Garcia, M.; Chan, W. C.; Ercilla, G.; FEBS Lett. 2003, 540, 133. 